\title{
Can muscle protein metabolism be specifically targeted by nutritional support and exercise training in chronic obstructive pulmonary disease?
}

\author{
Ramzi Lakhdar ${ }^{1}$, Roberto A. Rabinovich ${ }^{1,2}$ \\ ${ }^{1}$ ELEGI Colt Laboratory, MRC Centre for Inflammation Research, The Queen's Medical Research Institute, University of Edinburgh, Scotland, \\ UK; ${ }^{2}$ Respiratory Medicine Department, Royal Infirmary of Edinburgh, Scotland, UK \\ Contributions: (I) Conception and design: All authors; (II) Administrative support: All authors; (III) Provision of study materials or patients: None; \\ (IV) Collection and assembly of data: None; (V) Data analysis and interpretation: None; (VI) Manuscript writing: All authors; (VII) Final approval of \\ manuscript: All authors. \\ Correspondence to: Roberto A. Rabinovich. ELEGI Colt Laboratory, MRC Centre for Inflammation Research, The Queen's Medical Research \\ Institute, University of Edinburgh, 47 Little France Crescent. Edinburgh, Scotland EH16 4TJ, UK. Email: roberto.rabinovich@ed.ac.uk.
}

\begin{abstract}
Chronic obstructive pulmonary disease (COPD) associates with several extra-pulmonary effects. Muscle dysfunction and wasting is one of the most prominent extra-pulmonary effects and contributes to exercise limitation and health related quality of life (HRQoL), morbidity as well as mortality. The loss of muscle mass is characterised by an impaired balance between protein synthesis (anabolism) and protein breakdown (catabolism) which relates to nutritional disturbances, muscle disuse and the presence of a systemic inflammation, among other factors. Current approaches to reverse skeletal muscle dysfunction and wasting attain only modest improvements. The development of new therapeutic strategies aiming at improving skeletal muscle dysfunction and wasting are needed. This requires a better understanding of the underlying molecular pathways responsible for these abnormalities. In this review we update recent research on protein metabolism, nutritional depletion as well as physical (in)activity in relation to muscle wasting and dysfunction in patients with COPD. We also discuss the role of nutritional supplementation and exercise training as strategies to re-establish the disrupted balance of protein metabolism in the muscle of patients with COPD. Future areas of research and clinical practice directions are also addressed.
\end{abstract}

Keywords: Chronic obstructive pulmonary disease (COPD); muscle wasting/dysfunction; protein metabolism; nutritional support; exercise training

Submitted Mar 28, 2018. Accepted for publication May 08, 2018.

doi: $10.21037 /$ jtd.2018.05.81

View this article at: http://dx.doi.org/10.21037/jtd.2018.05.81

\section{Introduction}

The Global Initiative for chronic obstructive pulmonary disease (COPD) defines COPD as a "common, preventable, and treatable disease characterized by persistent respiratory symptoms and airflow limitation that is due to airway and/or alveolar abnormalities, usually caused by significant exposure to noxious particles or gases" $(1,2)$. The disease is associated with significant systemic effects. Skeletal muscle wasting, particularly in the limb muscles, is one of the most extensively studied $(3,4)$ and results in loss of muscle strength $(3,5-8)$, contributes to exercise limitation (9-12) and is a predictor of poor health related quality of life (HRQoL) (13), increased health care utilization (14) and poor survival $(15,16)$ independently of the degree of airway obstruction (12). A number of pathophysiological changes, have been identified in the skeletal muscle of patients with COPD namely atrophy of muscle fibres (9), fibre type redistribution (17), bioenergetics alteration (17), capillarization modification (18), and changed mitochondrial function $(19,20)$. 
The molecular mechanisms leading to skeletal muscle wasting are, to date, not fully comprehended and are likely to be multi-factorial. Several factors are thought to contribute to skeletal muscle wasting in COPD patients and may relate to muscle abnormalities characteristic of these patients. Among others, systemic inflammation (21), oxidative stress (22), cell hypoxia (23), accelerated ageing and cellular senescence (24-27), low physical activity levels (28), nutritional depletion (29) as well as loss of muscle protein have been reported as potential putative mechanisms.

The loss of skeletal muscle protein can result from the altered balance between muscle protein anabolism (protein synthesis) and catabolism (protein degradation). In the present review we discuss recent findings in muscle energy and protein balance in skeletal muscle of patients with COPD. We also address the role of nutritional support and exercise training as specific strategies to preserve muscle mass and function with a note on future research and clinical practice directions.

\section{Skeletal muscle energy and protein balance in COPD}

Skeletal muscle tissue undergoes continuous cycles of damage and repair. This muscle tissue remodelling is maintained by a tightly regulated protein metabolism and energy production processes, the efficiency of which will be reflected on the muscle mass.

Eighteen percent to $36 \%$ of COPD patients present muscle mass loss, which is responsible for weight loss, and is evident in $17 \%$ to $35 \%$ of COPD patients depending on the studied population (9,29-32). Six percent to $21 \%$ of patients with normal weight, indeed, present muscle wasting $(9,29,30)$. These different COPD body composition phenotypes highlights the fact that impairment in protein and energy balance may occur simultaneously (leading to a depletion of both body fat and protein) or may be dissociated (i.e., preserved energy balance but negative protein balance leading to muscle wasting with preserved body weight) (33).

Loss of muscle mass in patients with cachexia can be explained by an increased energy expenditure not matched by adequate calorie intake (34). In turn, a decreased appetite combined with a hyper-catabolic state can also cause a negative nutrition balance and eventually a loss of weight (35). A reduction in calorie intake has been proposed as one potential mechanism leading to a catabolic state in
COPD, as reported for acute exacerbations of COPD (36). In contrast, a reduction in calorie intake does not appear relevant in stable patients (36) but basal metabolism is increased (37), particularly in underweight patients (38). An increased oxygen uptake by the respiratory muscles is the classical explanation for the elevated energy expenditure characteristic of these patients (39). The increased oxygen consumption in relation to a specific task $(40,41)$ and the increased energy expenditure during activities of daily life $(42,43)$ can also play a role in the increased energy consumption in these patients. In addition, enhanced muscle protein turnover can also play a contributing role $(44,45)$.

Skeletal muscle plasticity is remarkable. Muscle mass depends on a delicate equilibrium between protein synthesis and degradation. Skeletal muscle adapts to the functional demands by adjusting the balance between protein synthesis and protein breakdown. The capacity of the muscle to self-regenerate also influences this equation $(27,46,47)$. The delicate equilibrium between protein synthesis and degradation is carefully regulated at a molecular level. An on-going imbalance in the processes of protein catabolism and synthesis is hypothesized to be the underlying mechanism leading to skeletal muscle wasting $(48,49)$.

\section{Protein synthesis}

Protein synthesis is a fundamental biological process that occurs in two major stages in the muscle cells. The first stage is initiated in the cell's nucleus, where a specific section of deoxyribonucleic acid (DNA) is transcripted to ribonucleic acid (RNA). This RNA molecule moves to the cell cytoplasm, where the translation (into an aminoacid chain) stage takes place and the actual process of protein synthesis starts. Protein synthesis is regulated by a complex system. Growth hormone (GH) exerts a diverse array of physiological actions that include prominent roles in growth and metabolism with the stimulation of the insulin-like growth factor (IGF-1) synthesis playing a major role (50). Circulating GH levels have a critical impact on the signalling pathways involved in skeletal muscle protein synthesis (51).

The IGF-1 pathway, mediated via AKT signalling pathway, has been recognised as a key mechanism to promote muscle growth $(48,52)$. In animal models, IGF1 induce protein synthesis and restrain protein breakdown in a dose-dependent manner in muscles from burned and unburned rats (53).

Activated (phosphorylated) AKT promotes protein 
synthesis. This action is mediated through phosphorylation of several proteins that results in the activation $[70-\mathrm{kD}$ ribosomal S6 protein (p70S6) kinase and rapamycin (mTOR)] or suppression [glycogen synthase kinase-3b (GSK3b)] of their action (54-56).

IGF-1 also down regulates atrogin- 1 by promoting FOXOs phosphorylation suppressing protein degradation (55). IGF-1 regulates GH release, such as in starvation conditions (48), but can also be affected by the nutritional and metabolic changes. COPD patients present low levels of circulating IGF-1 (48) that may relate to a reduction in muscle fibre diameter and hence muscle size (54).

Protein anabolism rests on the availability of essential amino acids (EAA). These, in turn, mediate intermediary metabolism. Therefore, analysis of the plasma levels of free amino acids may be useful for determining the characteristics of nitrogen metabolism and thus of protein malnutrition. Alterations in aminoacid metabolism and in plasma and muscle amino acid concentrations have been found in COPD patients. Previous studies have shown reduced plasma levels of branched-chain amino acids (BCAAs) [mainly leucine but also isoleucine and valine] in patients with COPD (57).

In addition, plasma concentrations of BCAAs correlated with intracellular $\mathrm{pH}$ and phosphocreatine ( $\mathrm{PCr}$ ) index at the completion of exercise, suggesting that BCAAs affect muscle energy metabolism during exercise in patients with COPD (58). Levels of muscle BCAAs in stable COPD patients appears to be similar to those in healthy age-matched controls (59), but are reduced in underweight COPD patients in comparison to COPD patients with preserved weight (60).

Plasma levels of phenylalanine and tyrosine amino acids have been reported in COPD patients to be either decreased, unaltered or increased (48,59,61-63). Plasma concentrations of alanine, glutamine and glutamate are reduced in patients with COPD with reduced body weight and FFM and moderate-to-severe airflow obstruction (59). In contrast, increased plasma concentrations of glutamine and glutamate were found in normal weight ambulatory patients with COPD (60), and higher glutamine concentrations in reduced body weight severe patients with emphysema (62).

The disturbance in skeletal muscle metabolism in these patients is highlighted by the changes observed in plasma and muscle concentrations of alanine, BCAAs, glutamine and glutamate (48). However, further studies investigating the regulation of amino acids transport between the muscle and the different organs will help to interpret the changes in these amino acids levels in COPD patients.

\section{Protein degradation}

The ubiquitin-proteasome pathway is the main suspect accountable for the majority of the accelerated degradation of muscle proteins in different conditions associated with muscle wasting (64). Muscle RING finger-1 (MuRF-1) and muscle atrophy F-box (MAFbx) have been studied in relation to the catabolism of skeletal muscle of COPD patients (65). Among others, nutrition and exercise training (muscle stimuli) are thought to affect MuRF-1 and MAFbx regulation. A recent study reported that ubiquitinproteasome system regulators (FOXO1 protein; p-FOXO3/ FOXO3), protein synthesis signaling (AKT1; p-GSK3B/ GSK3B; p-4E-BP1/4E-BP1), myogenic signaling (MYOG) were increased in COPD, and more prominently in those with sarcopenia, reflecting molecular alterations related to muscle repair and remodelling (66).

Other protein degradation pathways have been suggested. Smith et al. reported that calpain activation in skeletal muscle disrupted the sarcomere and allowed the release of myofilaments, which are subsequently ubiquitinated and degraded by the $26 \mathrm{~S}$ proteasome (67). Caspase- 3 activation has also been shown to cleave actomyosin providing substrates for the UbP system (68). Autophagy/ lysosomal pathways have been also counted as a protein degradation mechanism activated in coordination with ubiquitin proteasomal pathways (69). This pathway plays an important role in protein degradation in experimental models of muscle atrophy (70) and in vivo (71). We refer the reader to several reviews in this subject for a more extensive discussion on this topic $(48,72-74)$.

Several inflammatory cytokines namely the tumour necrosis factor- $\alpha$ (TNF- $\alpha$ ), interleukin (IL)-1, IL-6, and interferon gamma (IFN- $\gamma$ ) have been associated with the catabolic process with a varying relevance of each cytokine in different catabolic conditions $(48,64,75)$. The association between inflammation and hormonal changes is also confirmed by data from studies using different experimental models (48). The administration of interleukin-1 and TNF- $\alpha$ in animal models is associated with a reduction in plasma levels of IGF-1 and reduced protein synthesis (48). Transient exposure of myoblasts (or myotubes) to TNF- $\alpha$ inhibits protein synthesis (76). Thus, the anabolic actions of IGF-1 on muscle protein synthesis may occur during catabolic states where TNF- $\alpha$ is over expressed (76). Systemic inflammatory response can impact on muscle protein metabolism by increasing demand for amino acids to synthesise acute phase proteins in the liver, and also by 
the pro-inflammatory cytokines effect on muscle protein synthesis and degradation (48).

A close relationship between Metabolic Syndrome (MetS) and COPD has been described (77), which is associated with an increase in the levels of systemic inflammation and physical inactivity, irrespective of lung function impairment (77).

Vitamin D levels in both patients with MetS and COPD appeared to be reduced, suggesting a possible relationship between hypovitaminosis D and both diseases. A significant effect of cigarette smoking, the most common risk factor in COPD, was linked to vitamin D reduction regardless of the underlying disease (78).

\section{Treatment options}

The development of an effective treatment to revert muscle mass loss is yet to be achieved. There is, however, evidence of different strategies (i.e., hormonal or nutritional supplementation) aiming either at maintaining or increasing muscle mass in patients with COPD that showed promising results. In turn, different exercise-based training modalities have been successfully used to improve muscle dysfunction characteristic of patients with COPD. These modalities include aerobic and/or resistance training, high-intensity interval training, electrical or magnetic muscle stimulation, whole-body vibration, and water-based training. Muscle mass improvement has been described in association to exercise training in stable patients with COPD (79). In the following section we briefly reviewed the most relevant therapeutic interventions with clinical relevance to these patients.

\section{Hormonal and nutritional support in COPD}

The effect of nutritional support in COPD patients has shown controversial results but appears to be in-effective for improving weight in studies where patients were not stratified according to their nutritional status (80). A metaanalysis found that most of the studies included showed no beneficial effects of nutritional supplementation while some reported minor increase in body weight and physical function of unclear clinical relevance (81). The combination of a multifactorial pathogenesis, different phenotypes and the existence of associated comorbidities may explain this lack of consistent results and further research considering these aspects needs to be conducted.

Interestingly, the absence of any response to nutritional support has been linked to elevated levels of systemic inflammation markers (82). Moreover, nutritional support improved survival in those patients who gained more than $2 \mathrm{~kg}$ of weight (80) or $1 \mathrm{~kg} \cdot \mathrm{m}^{-2}$ of BMI (83). As a further matter, when specifically poorly nourished patients were targeted, nutritional support showed a positive effect in maintaining and improving weight gain, increasing fat free mass (FFM), fat mass (FM), 6-minute walk distance and skinfold thickness $(84,85)$.

Several studies have investigated the effect of proteins [branched chain amino acid (BCAAs), EAA], high fat, high calories, omega-3 and 6 polyunsaturated fatty acids (PUFA), antioxidants, vitamin D, C and E, GH and IGF, testosterone and other anabolic steroids and drugs in patients with COPD.

\section{Proteins: BCAAs and EAAs}

Although several studies have shown changes in plasma concentrations of amino acids in COPD patients, only few studies investigated the effect of BCAAs and EAAs nutrition support in these patients. BCAAs supplementation by soy protein enhances whole-body protein synthesis in COPD patients and alters inter-organ protein metabolism in favour of the peripheral (muscle) compartment in healthy elderly and even more in COPD patients (86).

It has been reported that low plasma BCAAs in COPD results from a low leucine concentration and altered leucine metabolism in these patients, associated with low FFM and increased insulin concentrations (57). Interestingly, leucine up-regulates protein synthesis in skeletal muscle by enhancing both the activity and synthesis of proteins involved in mRNA translation (87).

Oral supplementation of EAAs in 32 patients with severe COPD and sarcopenia produce a positive effect on muscle energy metabolism; blood oxygen tension, physical autonomy; cognitive function, and perception of health status in these patients (88). Another study demonstrated that in severe COPD patients unable to participate in a pulmonary rehabilitation programme, EAAs supplementation contributed to improving their daily-life performance, quality of life (QoL); nutritional and cognitive status as well as muscle strength (89).

\section{High fat, high calories, omega-3 PUFA}

Study assessing the efficacy of a high-fat, low-carbohydrate (CHO) nutritional supplement in COPD patients showed a significant improvement in their pulmonary function in comparison with the traditional high $\mathrm{CHO} \operatorname{diet}(90)$. 
De Batlle and colleagues (91) investigated the relationship between dietary intake of omega- 3 and omega-6 PUFA and serum inflammatory markers in tow hundred and fifty clinically stable COPD patients. They found that $\alpha$-linolenic acid (an omega-3 fatty acid with antiinflammatory properties) was associated with lower TNF- $\alpha$ concentrations.

Systemic low-grade inflammation, a feature of COPD, has been associated with increased plasma levels of acute phase proteins such as leptin (34), suggesting a relationship between the metabolic changes and the systemic inflammatory response in COPD. Leptin is an adipose tissue protein involved in the stimulation of appetite, dietary intake and energy expenditure. The poor response to nutritional support in some of the cachectic patients may be related to cytokineleptin link and may open a novel approach in combating this significant comorbidity in COPD (34).

\section{Vitamin D supplementation}

Vitamin D deficiency is common in patients with COPD and relates to a lower $\mathrm{FEV}_{1}$, impaired immunologic control, increased airways inflammation, reduced endurance shuttle walk time and higher dropout rates from pulmonary rehabilitation $(92,93)$. Only a few studies have investigated the role of vitamin D supplements in patients with COPD. High dose vitamin $\mathrm{D}$ supplementation during rehabilitation may have mild additional benefits to training (94). In another study, high-dose vitamin D supplementation showed a significant reduction in exacerbations in patients with severe vitamin $\mathrm{D}$ deficiency [serum $25-(\mathrm{OH}) \mathrm{D}$ levels $<10 \mathrm{ng} / \mathrm{mL}$ ], but not in those with higher circulating levels of vitamin D (92).

\section{Antioxidants}

Maintaining increased serum concentrations of dietary antioxidant vitamins and selenium may improve lung function (95). Serum levels of antioxidant vitamins, selenium, calcium, chloride, carotenes and iron were associated with higher $\mathrm{FEV}_{1}$ values in an independent manner $(95,96)$. Dietary intake patterns with increasing fruit, vegetables, fish, vitamin E, and whole grains in the diet has been associated with a decreased development of COPD in smokers and non-smokers, higher levels of $\mathrm{FEV}_{1}$, and decreased long-term COPD mortality (96). In addition, allopurinol, an xanthine oxidase inhibitor reducing reactive oxygen species (ROS) production, decreases blood glutathione oxidation and lipid peroxidation in COPD patients after exhaustive exercise (97).

Cyclooxygenase inhibitors and antioxidants (alpha-lipoic acid, carbocysteine lysine salt, vitamin E, vitamin A and vitamin C) administration significantly increased the body weight lean body mass and appetite in patients with cancer cachexia (98).

$\mathrm{N}$-acetylcysteine (NAC), a drug that supports glutathione synthesis, has been shown to lessen oxidation of cellular constituents and delay muscle fatigue (99). In a doubleblind, randomised study in healthy individuals, NAC attenuates muscle fatigue via improved potassium regulation during prolonged, submaximal endurance exercise (100). These have not been explored in COPD and may be a promising area for further research.

\section{GH and Insulin growth factor}

GH supplementation, its impact on muscle atrophy and its role on protein catabolism, have been studied in COPD with heterogeneous results. Subcutaneous injections of recombinant methionyl human $\mathrm{GH}(0.05 \mathrm{mg} / \mathrm{kg}$ daily) to malnourished patients with COPD showed a substantial weight gain during the first week of GH treatment, improved nitrogen balance and maximal inspiratory pressure (101). Daily administration of $0.15 \mathrm{IU} / \mathrm{kg}$ recombinant human growth hormone (rhGH) for 3 weeks increased lean body mass, however fail to impact muscle strength or exercise capacity in COPD patients with weight loss (102). However, the combination of $\mathrm{GH}$ and exercise training showed an increment in lean body mass not seen in the group receiving only exercise training (103).

There is still little information available regarding IGF levels in COPD (103). IGF-1 low levels in stable COPD patients are consistent with the believe that the GH axis is suppressed by chronic diseases (103).

Studies investigating the effect of GH as promoter of protein synthesis documented a modest gain in muscle mass in patients with COPD $(102,104)$ and proposed GH anabolic stimuli as an effective therapeutic strategy without causing adverse side effects. However, the GH is expensive, should be administered several times a week and its impact on muscle function is still to be elucidated. Further controlled studies of a larger patient group are needed to clarify the functional efficacy of GH in patients with COPD.

\section{Testosterone and other anabolic steroids}

Testosterone and other similar anabolic hormones induce 
an anabolic response in the muscle. This effect is mediated through the androgen receptor and by inhibiting the protein catabolic processes (48). This results in hypertrophy with an increase synthesis of actin and myosin heavy chains via somatomedin (48). Casaburi and colleagues found that men with COPD have high prevalence of low testosterone levels, which may contribute to muscle weakness (105). They showed that testosterone supplementation increased the lean body mass by an average of $2.3 \mathrm{~kg}$ when injected alone and $3.3 \mathrm{~kg}$ when combined with resistance training (105). A randomized controlled trial investigating the physiologic effects of nutritional intervention alone or combined with the anabolic steroid nandrolone decanoate showed that nutritional supplementation in combination with a short course of anabolic steroids improve FFM and respiratory muscle function in underweight patients with COPD (104). The effects of oxandrolone, an adjunct to help restore weight, were evaluated in patients with COPD. This testosterone analogue was found effective to facilitate weight restoration in these patients and the weight gain was primarily lean body mass (106).

However, due to its possible adverse effects, testosterone supplementation is not routinely recommended in COPD. Moreover, the clinical impact of testosterone on exercise tolerance, QoL, and survival is unknown as the available studies are only short term (4).

\section{Other anabolic drugs and bioactive nutrients}

Several pharmacologic agents have been described as anabolic agents as they have the potential to form complex macromolecules that store energy.

Administration of Megestrol acetate, a progestational appetite stimulant, showed an increased appetite and body weight, and stimulated ventilation, in underweight COPD patients, however this stimulation did not improve respiratory muscle function or exercise tolerance (107).

The administration of Creatine improves muscle strength in exercising healthy individuals, and in patients with neuromuscular disease and heart failure (108). However, a systematic review and meta-analysis found that creatine supplementation does not improve exercise capacity, muscle strength or HRQoL in patients with COPD receiving pulmonary rehabilitation (108).

The effects of combining L-carnitine with a combination of exercise training and inspiratory muscle training improved exercise tolerance and inspiratory muscle strength in COPD patients, as well as reducing lactate production during exercise (109). For further discussion of the nutritional supplementation and its effect on COPD patients, we draw the attention of the reader to excellent reviews on this subject $(110,111)$.

A short mention should be made regarding inhibition of protein degradation that can, in the future, complement strategies to stimulate protein anabolism. In this regard, some studies have investigated the potential beneficial role of protein degradation inhibition on muscle mass in experimental models. The incubation of rat skeletal muscle in the presence of hibernating bear plasma showed a decrease of proteolytic rate attributed to $\alpha 2$-macroglobulin, a non-specific protease inhibitor, present in higher levels in the winter bear plasma (112). The treatment of human myotubes with winter bear serum showed a significant inhibition of proteolysis and a slight decrease in protein synthesis with a subsequent improvement in protein content in these cells (113). These studies suggest that the identification of trans-species circulating components that maintain muscle mass may offer novel solutions to prevent and reverse human muscle mass loss.

\section{Exercise training in COPD}

Sedentary life style and the subsequent physical inactivity are counted as important contributing factor to muscle wasting and dysfunction in patients with COPD. Exercise training, is considered as the cornerstone of pulmonary rehabilitation and regarded as the best available treatment to improve muscle function in COPD patients. Many studies have assessed the relevance of exercise training on skeletal muscle structure and function $(114,115)$. Exercise training lead to a reduction of the percentage of type II fibres (116-118), increase in oxidative capacity $(41,116-121)$ with a reduction in early lactate release during exercise $(119,120)$ and an increase, although modest, in midthigh muscle cross-sectional area (105) and FFM (122). These adaptations to exercise training are related to an up-regulation of key factors governing skeletal muscle regeneration and hypertrophy such as IGF-1, mechanogrowth factor (MGF) and MyoD $(105,116,118,123)$, and an increase in satellite cells numbers (124) together with down-regulation of myostatin $(115,125)$. Moreover, exercise training appears to down-regulate the activity of protein breakdown pathways such as $\mathrm{NF}-\kappa \mathrm{B}$-activated $\mathrm{UbP}$ pathway (116).

The effect of exercise training on muscle and systemic inflammation and oxidative/nitrosative stress is controversial 
with studies showing no impact on the levels of systemic or local muscle inflammation $(118,123)$ and others showing a preventive effect of exercise training on systemic and muscle oxidative stress in severe COPD patients (126).

A significant reduction in most muscle amino acid levels after exercise was reported, whereas plasma levels of the amino acids were increased, suggesting enhanced amino acid release from the muscle during exercise in these patients (61). The authors conclude that exercise alters amino acid (intermediary) metabolism in patients with COPD independently of the presence of muscle wasting (61).

Irrespective of the induction of exercise-induced oxidative/ nitrosative stress $(127,128)$ or the significance and direction of changes in the expression of local muscle inflammatory mediators $(116,118,128)$ or aminoacid release, exercise training results in an improvement in muscle function (strength, endurance, and fatigability) (122,129-133). Better muscle function results in an improvement in exercise tolerance, QoL, and reduced dyspnoea and muscle fatigue $(134,135)$. The higher intensity of the training the greater its effect (136).

\section{Combining exercise training and nutritional support in COPD}

Combination of nutritional/anabolic support and exercise training can be a robust approach to obtaining improvements in patients with COPD with some studies supporting this approach (137).

The use of an anti-inflammatory nutritional supplement that contains whey peptide, a protein complex derived from milk, has the ability to act as an antioxidant, antitumour, and antiviral agent. The whey peptide was found to have an anti-inflammatory effect when administered alongside with exercise therapy in stable aged patients with COPD, inhibited systemic inflammation and increase body weight thereby improving exercise tolerance and HRQoL $(138,139)$. However, the nutrition support interventions in the same study did not modify significantly the systemic inflammatory and oxidative stress markers that were assessed (139). A study assessing the degree of systemic inflammation and the modifications in the concentrations of systemic C-reactive protein, TNF- $\alpha$, IL-6 and IL-8, before and after the combination of a nutritional support with low-intensity exercise showed that this combination was a successful strategy to enhance weight and energy intake as well as exercise capacity and HRQoL (137). Furthermore, major inflammatory cytokines levels decreased significantly after combining nutritional support with low-intensity exercise training (137).

\section{Conclusions, future research and clinical practice directions}

The imbalance between the protein degradation and synthesis leading to muscle wasting in COPD is a complex physio-pathogenic feature with the underlying molecular mechanisms still to be fully elucidated.

Although the effect of nutritional supplementation in COPD is controversial, the lack of effect seems to relate to the levels of systemic inflammation. Moreover, it has been shown to be effective in selected patients (i.e., malnourished) and, when a gain in weight is achieved, it is associated with a more favourable outcome. Similarly, specific supplements such as EAAs have shown positive effects when sarcopenic patients are targeted, alone or in combination to PR. Supplementation of vitamin D has shown modest effects, although, further research is needed in this field to recommend routine use. Some studies have shown a positive effect of antioxidants on exercise tolerance, but the evidence is scarce and further studies are encouraged in the field.

Hormone supplementation (i.e., GH), anabolic drugs and appetite stimulants lead to modest effects on body composition with little transference to improvements in exercise capacity. The cost, frequency of administration required, potential adverse effects for some of the components and lack of transference of effects to exercise tolerance, require further studies to gain more insight in this field.

A more targeted approach might be required to make the most of the several potentially beneficial interventions in relation to the specific patient's characteristics.

Exercise training is regarded as the best strategy to improve muscle function in patients with COPD and is associated with modest increase in muscle mass. Long programs with high intensity stimuli produce the greatest benefits. Future efforts in exploring the effects of different training modalities in COPD, together with the determination of the optimum intensity and duration of training, may help to develop tailored exercise programmes matched to the needs of each individual.

Few studies combining exercise and supplements have shown potential effects in levels of circulating inflammation, body weight and exercise capacity. Further studies assess the nutritional support and exercise training modalities, 
each alone and in combination, are needed to improve the clinical course of COPD. Increased dietary intake can compensate for elevated energy requirements; however, uncontrolled protein breakdown cannot be overcome by increasing protein synthesis alone. Understanding whether a reduction in muscle mass is a consequence of a reduction in protein anabolism, or an accelerated protein breakdown, or a combination of both, is crucial in the identification of the molecular pathways and direct treatments (48). A better understanding of the interrelation between protein degradation and synthesis in muscle, as well as in the other organs, and the implication of dietary intake in protein metabolism will be important.

Large scale studies involving well characterised populations and considering the co-morbidities of the patients are needed to elucidate the interrelations of dietary intake, low-grade systemic inflammation, body composition and physical activity characteristic in COPD and improve patient's clinical management.

\section{Acknowledgements}

Ellen Drost for proof reading the manuscript.

\section{Footnote}

Conflicts of Interest: The authors have no conflicts of interest to declare.

\section{References}

1. Vogelmeier CF, Criner GJ, Martinez FJ, et al. Global Strategy for the Diagnosis, Management, and Prevention of Chronic Obstructive Lung Disease 2017 Report. GOLD Executive Summary. Am J Respir Crit Care Med 2017;195:557-82.

2. Vogelmeier CF, Criner GJ, Martinez FJ, et al. Global Strategy for the Diagnosis, Management, and Prevention of Chronic Obstructive Lung Disease 2017 Report: GOLD Executive Summary. Arch Bronconeumol 2017;53:128-49.

3. Agustí AG, Noguera A, Sauleda J, et al. Systemic effects of chronic obstructive pulmonary disease. Eur Respir J 2003;21:347-60.

4. Maltais F, Decramer M, Casaburi R, et al. An official American Thoracic Society/European Respiratory Society statement: update on limb muscle dysfunction in chronic obstructive pulmonary disease. Am J Respir Crit Care Med 2014;189:e15-62.

5. Decramer M, Gosselink R, Troosters T, et al. Peripheral muscle weakness is associated with reduced survival in COPD. Am J Respir Crit Care Med 1998;157:A19.

6. Engelen MP, Schols AM, Does JD, et al. Skeletal muscle weakness is associated with wasting of extremity fat-free mass but not with airflow obstruction in patients with chronic obstructive pulmonary disease. Am J Clin Nutr 2000;71:733-8.

7. Bernard S, Leblanc P, Whittom F, et al. Peripheral Muscle Weakness in Patients with Chronic Obstructive Pulmonary Disease. Am J Respir Crit Care Med 1998;158:629-34.

8. Vilaro J, Rabinovich R, Gonzalez-deSuso JM, et al. Clinical assessment of peripheral muscle function in patients with chronic obstructive pulmonary disease. Am J Phys Med Rehabil 2009;88:39-46.

9. Schols AM, Soeters PB, Dingemans AM, et al. Prevalence and characteristics of nutritional depletion in patients with stable COPD eligible for pulmonary rehabilitation. Am Rev Respir Dis 1993;147:1151-6.

10. Baarends EM, Schols AM, Mostert R, et al. Peak exercise response in relation to tissue depletion in patients with chronic obstructive pulmonary disease. Eur Respir J 1997;10:2807-13.

11. Kobayashi A, Yoneda T, Yoshikawa M, et al. The relation of fat-free mass to maximum exercise performance in patients with chronic obstructive pulmonary disease. Lung 2000;178:119-27.

12. Schols AM, Mostert R, Soeters PB, et al. Body composition and exercise performance in patients with chronic obstructive pulmonary disease. Thorax 1991;46:695-9.

13. Mostert R, Goris A, Weling-Scheepers C, et al. Tissue depletion and health related quality of life in patients with chronic obstructive pulmonary disease. Respiratory Medicine 2000;94:859-67.

14. Decramer M, Gosselink LE, Troosters T, et al. Muscle weakness is related to utilization of health care resources in COPD patients. Eur Respir J 1997;10:417-23.

15. Marquis K, Debigare R, Lacasse Y, et al. Midthigh muscle cross-sectional area is a better predictor of mortality than body mass index in patients with chronic obstructive pulmonary disease. Am J Respir Crit Care Med 2002;166:809-13.

16. Mador MJ. Muscle mass, not body weight, predicts outcome in patients with chronic obstructive pulmonary disease. Am J Respir Crit Care Med 2002;166:787-9.

17. Jakobsson P, Jorfeldt L, Brundin A. Skeletal muscle 
metabolits and fibre types in patients with advanced chronic obstructive pulmonary disease (COPD), with and without chronic respiratory failure. Eur Respir J 1990;3:192-6.

18. Simard C, Maltais F, Leblanc P, et al. Mitochondrial and Capillarity Changes in Vastus Lateralis Muscle of COPD Patients: Electron Microscopy Study. MedSciSports Exerc 1996;28:S95.

19. Rabinovich RA, Bastos R, Ardite E, et al. Mitochondrial Dysfunction in COPD Patients with low Body Mass Index. Eur Respir J 2007;29:643-50.

20. Puente-Maestu L, Perez-Parra J, Godoy R, et al. Abnormal mitochondrial function in locomotor and respiratory muscles of COPD patients. Eur Respir J 2009;33:1045-52.

21. van Helvoort HA, van de Pol MH, Heijdra YF, et al. Systemic inflammatory response to exhaustive exercise in patients with chronic obstructive pulmonary disease. Respir Med 2005;99:1555-67.

22. MacNee W, Rahman I. Is oxidative stress central to the pathogenesis of chronic obstructive pulmonary disease? Trends in molecular medicine 2001;7:55-62.

23. Koechlin C, Maltais F, Saey D, et al. Hypoxaemia enhances peripheral muscle oxidative stress in chronic obstructive pulmonary disease. Thorax 2005;60:834-41.

24. Ito K, Mercado N. STOP accelerating lung aging for the treatment of COPD. Exp Gerontol 2014;59:21-7.

25. Rabinovich RA, Drost E, Manning JR, et al. Genome-wide mRNA expression profiling in vastus lateralis of COPD patients with low and normal fat free mass index and healthy controls. Respir Res 2015;16:1.

26. Lakhdar R, Drost EM, MacNee W, et al. 2D-DIGE proteomic analysis of vastus lateralis from COPD patients with low and normal fat free mass index and healthy controls. Respir Res 2017;18:81.

27. Thériault ME, Pare ME, Maltais F, et al. Satellite cells senescence in limb muscle of severe patients with COPD. PLoS One 2012;7:e39124.

28. Watz H, Waschki B, Meyer T, et al. Physical activity in patients with COPD. Eur Respir J 2009;33:262-72.

29. Engelen MP, Schols AM, Baken WC, et al. Nutritional depletion in relation to respiratory and peripheral skeletal muscle function in out-patients with COPD. Eur Respir J 1994;7:1793-7.

30. Eid AA, Ionescu AA, Nixon LS, et al. Inflammatory response and body composition in chronic obstructive pulmonary disease. Am J Respir Crit Care Med 2001;164:1414-8.

31. Braun SR, Keim NL, Dixon RM, et al. The prevalence and determinants of nutritional changes in chronic obstructive pulmonary disease. Chest 1984;86:558-63.

32. Gray-Donald K, Gibbons L, Shapiro SH, et al. Effect of nutritional status on exercise performance in patients with chronic obstructive pulmonary disease. Am Rev Respir Dis 1989;140:1544-8.

33. Remels AH, Gosker HR, Langen RC, et al. The mechanisms of cachexia underlying muscle dysfunction in COPD. J Appl Physiol (1985) 2013;114:1253-62.

34. Schols AM, Creutzberg EC, Buurman WA, et al. Plasma leptin is related to proinflammatory status and dietary intake in patients with chronic obstructive pulmonary disease. Am J Respir Crit Care Med 1999;160:1220-6.

35. Schols AM. Nutritional and metabolic modulation in chronic obstructive pulmonary disease management. Eur Respir J Suppl 2003;46:81s-6s.

36. Schols AM, Wouters EF. Nutritional abnormalities and supplementation in chronic obstructive pulmonary disease. Clin Chest Med 2000;21:753-62.

37. Schols AM, Soeters PB, Mostert R, et al. Energy balance in chronic obstructive pulmonary disease. Am Rev Respir Dis $1991 ; 143: 1248-52$.

38. Wilson DO, Donahoe M, Rogers RM, et al. Metabolic rate and weight loss in chronic obstructive lung disease. JPEN J Parenter Enteral Nutr 1990;14:7-11.

39. Baarends EM, Schols AM, Slebos DJ, et al. Metabolic and ventilatory response pattern to arm elevation in patients with COPD and helathy age-matched subjects. Eur Respir J 1995;8:1345-51.

40. Richardson RS, Leek BT, Gavin TP, et al. Reduced mechanical efficiency in chronic obstructive pulmonary disease but normal peak VO2 with small muscle mass exercise. Am J Respir Crit Care Med 2004;169:89-96.

41. Sala E, Roca J, Marrades RM, et al. Effects of endurance training on skeletal muscle bioenergetics in chronic obstructive pulmonary disease. Am J Respir Crit Care Med 1999; 159:1726-34.

42. Baarends EM, Schols AM, Pannemans DL, et al. Total free living energy expenditure in patients with severe COPD. Am J Respir Crit Care Med 1997;155:549-54.

43. Hugli O, Schutz Y, Fitting JW. The daily energy expenditure in stable chronic obstructive pulmonary disease. Am J Respir Crit Care Med 1996;153:294-300.

44. Kao CC, Hsu JW, Bandi V, et al. Resting energy expenditure and protein turnover are increased in patients with severe chronic obstructive pulmonary disease. Metabolism 2011;60:1449-55.

45. Reid MB. Invited Review: redox modulation of skeletal 
muscle contraction: what we know and what we don't. J Appl Physiol (1985) 2001;90:724-31.

46. Eliason G, Abdel-Halim S, Arvidsson B, et al. Physical performance and muscular characteristics in different stages of COPD. Scand J Med Sci Sports 2009;19:865-70.

47. Plant PJ, Brooks D, Faughnan M, et al. Cellular markers of muscle atrophy in chronic obstructive pulmonary disease. Am J Respir Cell Mol Biol 2010;42:461-71.

48. Jagoe RT, Engelen MP. Muscle wasting and changes in muscle protein metabolism in chronic obstructive pulmonary disease. Eur Respir J Suppl 2003;46:52s-63s.

49. Wouters EF, Creutzberg EC, Schols AM. Systemic effects in COPD. Chest 2002;121:127S-30S.

50. Chia DJ. Minireview: mechanisms of growth hormonemediated gene regulation. Mol Endocrinol 2014;28:1012-25.

51. Consitt LA, Saneda A, Saxena G, et al. Mice overexpressing growth hormone exhibit increased skeletal muscle myostatin and MuRF1 with attenuation of muscle mass. Skelet Muscle 2017;7:17.

52. Vandenburgh HH, Karlisch P, Shansky J, et al. Insulin and IGF-I induce pronounced hypertrophy of skeletal myofibers in tissue culture. Am J Physiol 1991;260:C475-84.

53. Fang CH, Li BG, Wang JJ, et al. Insulin-like growth factor 1 stimulates protein synthesis and inhibits protein breakdown in muscle from burned rats. JPEN J Parenter Enteral Nutr 1997;21:245-51.

54. Glass DJ. Skeletal muscle hypertrophy and atrophy signaling pathways. Int J Biochem Cell Biol 2005;37:1974-84.

55. Sandri M, Sandri C, Gilbert A, et al. Foxo transcription factors induce the atrophy-related ubiquitin ligase atrogin-1 and cause skeletal muscle atrophy. Cell 2004;117:399-412.

56. Rommel C, Bodine SC, Clarke BA, et al. Mediation of IGF-1-induced skeletal myotube hypertrophy by $\mathrm{PI}(3) \mathrm{K} /$ Akt/mTOR and PI(3)K/Akt/GSK3 pathways. Nat Cell Biol 2001;3:1009-13.

57. Engelen MP, Wouters EF, Deutz NE, et al. Factors contributing to alterations in skeletal muscle and plasma amino acid profiles in patients with chronic obstructive pulmonary disease. Am J Clin Nutr 2000;72:1480-7.

58. Kutsuzawa T, Shioya S, Kurita D, et al. Plasma branchedchain amino acid levels and muscle energy metabolism in patients with chronic obstructive pulmonary disease. Clin Nutr 2009;28:203-8.

59. Pouw EM, Schols AM, Deutz NE, et al. Plasma and muscle amino acid levels in relation to resting energy expenditure and inflammation in stable chronic obstructive pulmonary disease. Am J Respir Crit Care Med
1998;158:797-801.

60. Yoneda T, Yoshikawa M, Fu A, et al. Plasma levels of amino acids and hypermetabolism in patients with chronic obstructive pulmonary disease. Nutrition 2001;17:95-9.

61. Engelen MP, Wouters EF, Deutz NE, et al. Effects of exercise on amino acid metabolism in patients with chronic obstructive pulmonary disease. Am J Respir Crit Care Med 2001;163:859-64.

62. Hofford JM, Milakofsky L, Vogel WH, et al. The nutritional status in advanced emphysema associated with chronic bronchitis. A study of amino acid and catecholamine levels. Am Rev Respir Dis 1990;141:902-8.

63. Førli L, Pedersen JI, Bjørtuft, et al. Serum amino acids in relation to nutritional status, lung function and energy intake in patients with advanced pulmonary disease. Respir Med 2000;94:868-74.

64. Debigaré R, Marquis K, Cote CH, et al. Catabolic/ anabolic balance and muscle wasting in patients with COPD. Chest 2003;124:83-9.

65. Rom O, Reznick AZ. The role of E3 ubiquitin-ligases MuRF-1 and MAFbx in loss of skeletal muscle mass. Free Radic Biol Med 2016;98:218-30.

66. Kneppers AE, Langen RCJ, Gosker HR, et al. Increased Myogenic and Protein Turnover Signaling in Skeletal Muscle of Chronic Obstructive Pulmonary Disease Patients With Sarcopenia. J Am Med Dir Assoc 2017;18:637.e1-11.

67. Smith IJ, Lecker SH, Hasselgren PO. Calpain activity and muscle wasting in sepsis. Am J Physiol Endocrinol Metab 2008;295:e762.

68. Du J, Wang X, Miereles C, et al. Activation of caspase-3 is an initial step triggering accelerated muscle proteolysis in catabolic conditions. J Clin Invest 2004;113:115-23.

69. Zhao J, Brault JJ, Schild A, et al. FoxO3 coordinately activates protein degradation by the autophagic/lysosomal and proteasomal pathways in atrophying muscle cells. Cell Metab 2007;6:472-83.

70. McClung JM, Judge AR, Powers SK, et al. p38 MAPK links oxidative stress to autophagy-related gene expression in cachectic muscle wasting. Am J Physiol Cell Physiol 2010;298:C542.

71. Mammucari C, Milan G, Romanello V, et al. FoxO3 controls autophagy in skeletal muscle in vivo. Cell Metab 2007;6:458-71.

72. Reid MB, Li YP. Tumor necrosis factor-alpha and muscle wasting: a cellular perspective. Respir Res 2001;2:269-72.

73. Mitch WE, Goldberg AL. Mechanisms of muscle wasting. The role of the ubiquitin-proteasome pathway. N Engl J 
Med 1996;335:1897-905.

74. Zhou J, Liu B, Liang C, et al. Cytokine Signaling in Skeletal Muscle Wasting. Trends Endocrinol Metab 2016;27:335-47.

75. Wouters EF, Creutzberg EC, Schols AM. Systemic effects in COPD. Chest 2002;121:127S-30S.

76. Frost RA, Lang CH, Gelato MC. Transient exposure of human myoblasts to tumor necrosis factor-alpha inhibits serum and insulin-like growth factor-I stimulated protein synthesis. Endocrinology 1997;138:4153-9.

77. Watz H, Waschki B, Kirsten A, et al. The metabolic syndrome in patients with chronic bronchitis and COPD: frequency and associated consequences for systemic inflammation and physical inactivity. Chest 2009;136:1039-46.

78. Piazzolla G, Castrovilli A, Liotino V, et al. Metabolic syndrome and Chronic Obstructive Pulmonary Disease (COPD): The interplay among smoking, insulin resistance and vitamin D. PLoS One 2017;12:e0186708.

79. De Brandt J, Spruit MA, Hansen D, et al. Changes in lower limb muscle function and muscle mass following exercise-based interventions in patients with chronic obstructive pulmonary disease: A review of the Englishlanguage literature. Chron Respir Dis 2018;15:182-219.

80. Schols AM, Slangen J, Volovics L, et al. Weight loss is a reversible factor in the prognosis of chronic obstructive pulmonary disease. Am J Respir Crit Care Med 1998;157:1791-7.

81. Akner G, Larsson K. Undernutrition state in patients with chronic obstructive pulmonary disease. A critical appraisal on diagnostics and treatment. Respir Med 2016;117:81-91.

82. Creutzberg EC, Schols AM, Weling-Scheepers CA, et al. Characterization of nonresponse to high caloric oral nutritional therapy in depleted patients with chronic obstructive pulmonary disease. Am J Respir Crit Care Med 2000;161:745-52.

83. Prescott E, Almdal T, Mikkelsen KL, et al. Prognostic value of weight change in chronic obstructive pulmonary disease: results from the Copenhagen City Heart Study. Eur Respir J 2002;20:539-44.

84. Ferreira IM, Brooks D, White J, et al. Nutritional supplementation for stable chronic obstructive pulmonary disease. Cochrane Database Syst Rev 2012;12:CD000998.

85. Berthon BS, Wood LG. Nutrition and respiratory health-feature review. Nutrients 2015;7:1618-43.

86. Engelen MP, Rutten EP, De Castro CL, et al. Supplementation of soy protein with branched-chain amino acids alters protein metabolism in healthy elderly and even more in patients with chronic obstructive pulmonary disease. Am J Clin Nutr 2007;85:431-9.

87. Anthony JC, Anthony TG, Kimball SR, et al. Signaling pathways involved in translational control of protein synthesis in skeletal muscle by leucine. J Nutr 2001;131:856S-60S.

88. Dal Negro RW, Aquilani R, Bertacco S, et al. Comprehensive effects of supplemented essential amino acids in patients with severe COPD and sarcopenia. Monaldi Arch Chest Dis 2010;73:25-33.

89. Dal Negro RW, Testa A, Aquilani R, et al. Essential amino acid supplementation in patients with severe COPD: a step towards home rehabilitation. Monaldi Arch Chest Dis 2012;77:67-75.

90. Cai B, Zhu Y, Ma Y, et al. Effect of supplementing a highfat, low-carbohydrate enteral formula in COPD patients. Nutrition 2003;19:229-32.

91. de Batlle J, Sauleda J, Balcells E, et al. Association between Omega3 and Omega6 fatty acid intakes and serum inflammatory markers in COPD. J Nutr Biochem 2012;23:817-21.

92. Lehouck A, Mathieu C, Carremans C, et al. High doses of vitamin $\mathrm{D}$ to reduce exacerbations in chronic obstructive pulmonary disease: a randomized trial. Ann Intern Med 2012;156:105-14.

93. Ringbaek T, Martinez G, Durakovic A, et al. Vitamin $\mathrm{d}$ status in patients with chronic obstructive pulmonary disease who participate in pulmonary rehabilitation. J Cardiopulm Rehabil Prev 2011;31:261-7.

94. Hornikx M, Van Remoortel H, Lehouck A, et al. Vitamin $\mathrm{D}$ supplementation during rehabilitation in COPD: a secondary analysis of a randomized trial. Respir Res 2012;13:84.

95. McKeever TM, Lewis SA, Smit HA, et al. A multivariate analysis of serum nutrient levels and lung function. Respir Res 2008;9:67.

96. Hanson C, Rutten EP, Wouters EF, et al. Diet and vitamin $\mathrm{D}$ as risk factors for lung impairment and COPD. Transl Res 2013;162:219-36.

97. Heunks LM, Vina J, van Herwaarden CL, et al. Xanthine oxidase is involved in exercise-induced oxidative stress in chronic obstructive pulmonary disease. Am J Physiol 1999;277:R1697-704.

98. Mantovani G, Maccio A, Madeddu C, et al. A phase II study with antioxidants, both in the diet and supplemented, pharmaconutritional support, progestagen, and anticyclooxygenase-2 showing efficacy and safety in patients with cancer-related anorexia/cachexia and oxidative stress. 
Cancer Epidemiol Biomarkers Prev 2006;15:1030-4.

99. Ferreira LF, Reid MB. Muscle-derived ROS and thiol regulation in muscle fatigue. J Appl Physiol (1985) 2008;104:853-60.

100.McKenna MJ, Medved I, Goodman CA, et al. $\mathrm{N}$-acetylcysteine attenuates the decline in muscle $\mathrm{Na}+\mathrm{K}+-$ pump activity and delays fatigue during prolonged exercise in humans. J Physiol 2006;576:279-88.

101.Pape GS, Friedman M, Underwood LE, et al. The effect of growth hormone on weight gain and pulmonary function in patients with chronic obstructive lung disease. Chest 1991;99:1495-500.

102. Burdet L, de Muralt B, Schutz Y, et al. Administration of growth hormone to underweight patients with chronic obstructive pulmonary disease. A prospective, randomized, controlled study. Am J Respir Crit Care Med 1997;156:1800-6.

103. Creutzberg EC, Casaburi R. Endocrinological disturbances in chronic obstructive pulmonary disease. Eur Respir J Suppl 2003;46:76s-80s.

104. Schols AM, Soeters PB, Mostert R, et al. Physiologic effects of nutritional support and anabolic steroids in patients with chronic obstructive pulmonary disease. A placebo-controlled randomized trial. Am J Respir Crit Care Med 1995;152:1268-74.

105. Casaburi R, Bhasin S, Cosentino L, et al. Effects of testosterone and resistance training in men with chronic obstructive pulmonary disease. Am J Respir Crit Care Med 2004;170:870-8.

106. Yeh SS, DeGuzman B, Kramer T. Reversal of COPDassociated weight loss using the anabolic agent oxandrolone. Chest 2002;122:421-8.

107. Weisberg J, Wanger J, Olson J, et al. Megestrol acetate stimulates weight gain and ventilation in underweight COPD patients. Chest 2002;121:1070-8.

108.Al-Ghimlas F, Todd DC. Creatine supplementation for patients with COPD receiving pulmonary rehabilitation: a systematic review and meta-analysis. Respirology 2010;15:785-95.

109. Borghi-Silva A, Baldissera V, Sampaio LM, et al. L-carnitine as an ergogenic aid for patients with chronic obstructive pulmonary disease submitted to whole-body and respiratory muscle training programs. Braz J Med Biol Res 2006;39:465-74.

110. Hsieh MJ, Yang TM, Tsai YH. Nutritional supplementation in patients with chronic obstructive pulmonary disease. J Formos Med Assoc 2016;115:595-601.

111. Rawal G, Yadav S. Nutrition in chronic obstructive pulmonary disease: A review. J Transl Int Med 2015;3:151-4.

112. Fuster G, Busquets S, Almendro V, et al. Antiproteolytic effects of plasma from hibernating bears: a new approach for muscle wasting therapy? Clin Nutr 2007;26:658-61.

113. Chanon S, Chazarin B, Toubhans B, et al. Proteolysis inhibition by hibernating bear serum leads to increased protein content in human muscle cells. Sci Rep 2018;8:5525.

114. Kirsten DK, Taube C, Lehnigk B, et al. Exercise training improves recovery in patients with COPD after an acute exacerbation. Respir Med 1998;92:1191-8.

115. Porszasz J, Emtner M, Goto S, et al. Exercise training decreases ventilatory requirements and exercise-induced hyperinflation at submaximal intensities in patients with COPD. Chest 2005;128:2025-34.

116. Vogiatzis I, Simoes DC, Stratakos G, et al. Effect of pulmonary rehabilitation on muscle remodelling in cachectic patients with COPD. Eur Respir J 2010;36:301-10.

117. Vogiatzis I, Terzis G, Nanas S, et al. Skeletal muscle adaptations to interval training in patients with advanced COPD. Chest 2005;128:3838-45.

118. Vogiatzis I, Stratakos G, Simoes DC, et al. Effects of rehabilitative exercise on peripheral muscle TNFalpha, IL-6, IGF-I and MyoD expression in patients with COPD. Thorax 2007;62:950-6.

119. Maltais F, Leblanc P, Simard C, et al. Skeletal muscle adaptation to endurance training in patients with Chronic Obstructive Pulmonary Disease. Am J Respir Crit Care Med 1996;154:442-7.

120. Casaburi R, Patessio A, Ioli F, et al. Reductions in exercise lactic acidosis and ventilation as a result of exercise training in patients with obstructive lung disease. American Review of Respiratory Disease 1991;143:9-18.

121. Wüst RC, Degens H. Factors contributing to muscle wasting and dysfunction in COPD patients. Int J Chron Obstruct Pulmon Dis 2007;2:289-300.

122. Bernard S, Whittom F, Leblanc P, et al. Aerobic and strength training in patients with chronic obstructive pulmonary disease. Am J Respir Crit Care Med 1999;159:896-901.

123. Bolton CE, Broekhuizen R, Ionescu AA, et al. Cellular protein breakdown and systemic inflammation are unaffected by pulmonary rehabilitation in COPD. Thorax 2007;62:109-14.

124. Menon MK, Houchen L, Singh SJ, et al. Inflammatory and satellite cells in the quadriceps of patients with COPD and response to resistance training. Chest 2012;142:1134-42.

125.Lewis MI, Fournier M, Storer TW, et al. Skeletal muscle 
adaptations to testosterone and resistance training in men with COPD. J Appl Physiol (1985) 2007;103:1299-310.

126. Rodriguez DA, Kalko S, Puig-Vilanova E, et al. Muscle and blood redox status after exercise training in severe COPD patients. Free Radic Biol Med 2012;52:88-94.

127. Barreiro E, Rabinovich R, Marin-Corral J, et al. Chronic endurance exercise induces quadriceps nitrosative stress in patients with severe COPD. Thorax 2009;64:13-9.

128. Rabinovich RA, Figueras M, Ardite E, et al. Increased tumour necrosis factor-alpha plasma levels during moderate-intensity exercise in COPD patients. Eur Respir J 2003;21:789-94.

129. Mador MJ, Kufel TJ, Pineda LA, et al. Effect of pulmonary rehabilitation on quadriceps fatiguability during exercise. Am J Respir Crit Care Med 2001;163:930-5.

130. Troosters T, Gosselink R, Decramer M. Short- and longterm effects of outpatient rehabilitation in patients with chronic obstructive pulmonary disease: a randomized trial. Am J Med 2000;109:207-12.

131. Spruit MA, Gosselink R, Troosters T, et al. Resistance versus endurance training in patients with COPD and peripheral muscle weakness. Eur Respir J 2002;19:1072-8.

132. O'Donnell DE, McGuire M, Samis L, et al. General exercise training improves ventilatory and peripheral muscle strength and endurance in chronic airflow limitation. Am J Respir Crit Care Med 1998;157:1489-97.

133. Ortega F, Toral J, Cejudo P, et al. Comparison of effects of strength and endurance training in patients with chronic obstructive pulmonary disease. Am J Respir Crit Care Med 2002;166:669-74.

134. Spruit MA, Singh SJ, Garvey C, et al. An official American Thoracic Society/European Respiratory Society statement: key concepts and advances in pulmonary rehabilitation. Am J Respir Crit Care Med 2013;188:e13-64.

135. Gloeckl R, Marinov B, Pitta F. Practical recommendations for exercise training in patients with COPD. Eur Respir Rev 2013;22:178-86.

136. Casaburi R. Skeletal muscle dysfunction in chronic obstructive pulmonary disease. Med Sci Sports Exerc 2001;33:S662-70.

137. Sugawara K, Takahashi H, Kasai C, et al. Effects of nutritional supplementation combined with low-intensity exercise in malnourished patients with COPD. Respir Med 2010;104:1883-9.

138. Sugawara K, Takahashi H, Kashiwagura T, et al. Effect of anti-inflammatory supplementation with whey peptide and exercise therapy in patients with COPD. Respir Med 2012;106:1526-34.

139. Laviolette L, Lands LC, Dauletbaev N, et al. Combined effect of dietary supplementation with pressurized whey and exercise training in chronic obstructive pulmonary disease: a randomized, controlled, double-blind pilot study. J Med Food 2010;13:589-98.
Cite this article as: Lakhdar R, Rabinovich RA. Can muscle protein metabolism be specifically targeted by nutritional support and exercise training in chronic obstructive pulmonary disease? J Thorac Dis 2018;10(Suppl 12):S1377-S1389. doi: $10.21037 /$ jtd.2018.05.81 